Dikirim: 16 Oktober 2015 Diterbitkan: 1 Maret 2016

\section{Kualitas udara ambien dan fungsi paru siswa sekolah dasar di Yogyakarta}

\author{
Ambient air quality and lung function of elementary school \\ students in Yogyakarta
}

Anjas Wulansari ${ }^{1}$, Sarto $^{2}$, Yusrizal Djam'an Saleh ${ }^{3}$

\begin{abstract}
Purpose: The purpose of this study was to analyze the association between ambient air level and lung function of elementary school students. Methods: This research was an observational study on 115 students from 6 schools. Research variables were ambient air pollution $\left(\mathrm{SO}_{2}, \mathrm{NO}_{2}, \mathrm{O}_{3}\right.$, and TSP) and lung function (Peak Expiratory Flow Rate - PEFR). Data analysis used chi-square test, Mann Whitney and logistic regression tests. Results: The ambient air quality among elementary school students in solid and non-solid traffic environments is still below the required threshold values. There was a relationship between $\mathrm{SO}_{2}, \mathrm{NO}_{2}, \mathrm{O}_{3}$, and TSP $(\mathrm{p}<0.05)$ in ambient air with lung function of children and TSP levels in ambient air became the main factor associated with lung function after multivariate analysis with school location factor, type sex, nutritional status, cigarette exposure, and exercise habits. Conclusion: The main factors that affect the lung function of students are cigarette exposure, exercise habits and TSP levels. The head master need to activate school health units and little doctors to keep students away from smoke exposure.
\end{abstract}

Keywords: ambient air quality; lung function; elementary school students

\footnotetext{
${ }^{1}$ Departemen Perilaku Kesehatan, Lingkungan dan Kedokteran Sosial, Fakultas Kedokteran, Universitas Gadjah Mada (Email: anjaswulansari@mail.ugm.ac.id)

${ }^{2}$ Departemen Teknik Kimia, Fakultas Teknik, Universitas Gadjah Mada

${ }^{3}$ Departemen Ilmu Penyakit Dalam, Fakultas Kedokteran, Universitas Gadjah Mada
} 


\section{PENDAHULUAN}

Kepadatan lalu lintas jalan di Yogyakarta semakin bertambah setiap tahun. Seiring dengan peningkatan jumlah kendaraan bermotor sebesar 15\% per tahun. Kapasitas jalan tidak sebanding dengan pertambahan jumlah kendaraan dapat meningkatkan kemacetan di berbagai titik ruas jalan. Jumlah kendaraan yang semakin banyak memadati jalan, menjadi salah satu sumber pencemaran udara (1,2). Tujuh puluh persen sumber pencemar udara di kota besar Indonesia berasal dari aktivitas kendaraan bermotor. Kota Yogyakarta merupakan salah satu kota dengan level of service (LOS) atau tingkat pelayanan jalan yang rendah. Kategori LOS di kota Yogyakarta berada di level F yang berarti arus terhambat, kecepatan rendah, volume di atas kapasitas, dan banyak berhenti. Kepadatan kendaraan dan kemacetan lalu lintas berpengaruh terhadap peningkatan polusi udara $(3,4)$.

Lingkungan sekolah adalah tempat dimana anak menghabiskan sebagian waktunya. Pada umumnya, sekolah berada di lokasi strategis, mudah dijangkau, dan berada di tepi jalan yang tidak jauh dari tempat tinggal anak. Anak-anak yang tinggal di rumah dengan jarak <500 meter dari jalan raya akan mengalami gangguan perkembangan fungsi paru $(5,6)$.

Fungsi paru merupakan salah satu indikator awal yang digunakan untuk mendeteksi penyakit jalan napas. Pengobatan pada orang dengan penyakit paru kronis seringkali mengecewakan, dengan mengetahui gangguan fungsi paru pada stadium awal diharapkan keparahan diperlambat $(7,8,9)$. Penelitian sebelumnya menunjukkan hasil kontradiktif tentang hubungan Kualitas udara ambien dengan fungsi paru anak (10). Idealnya, anak sekolah dasar lebih rentan mengalami paparan udara yang tercemar karena lebih sering berada di luar rumah. Oleh karena itu penelitian ini dilakukan untuk melihat hubungan kualitas udara ambien dengan fungsi paru anak sekolah dasar.

\section{METODE}

Jenis penelitian adalah penelitian observasional analitik, Subyek penelitian berjumlah 115 siswa dari enam sekolah dasar. Subjek adalah siswa kelas lima dengan kriteria inklusi adalah siswa bersekolah di sekolah tersebut mulai dari kelas 1 (bukan siswa pindahan dari sekolah lain); Siswa tinggal di rumah dengan jarak maksimal 1.500 meter dari jalan yang sama dengan lokasi sekolah. Kriteria eksklusi adalah mempunyai riwayat penyakit paru yaitu menderita penyakit TB paru, bronkitis, radang paru, dan asma. Pengambilan sampel udara dilaksanakan bersama tim dari laboratorium Fisika, Kimia, Gas dan Radiasi BBTKLPP Yogyakarta. Pengukuran antropometri dan fungsi paru siswa bersama fisioterapis dari RSKP Respira Yogyakarta. Analisis yang dilakukan adalah analisis univariat, analisis bivariat (uji chi-square untuk variabel kategorik, dan uji Mann Whitney untuk variabel numerik; dan analisis multivariat menggunakan uji regresi logistik.

\section{HASIL}

Dari hasil pengukuran kualitas udara ambien pada rerata semua parameter $\left(\mathrm{SO}_{2}, \mathrm{NO}_{2}, \mathrm{O}_{3}\right.$, TSP) yang diukur masih berada di bawah syarat baku mutu sesuai Peraturan Pemerintah Nomor 41 tahun 1999 tentang pengendalian pencemaran udara. Terdapat perbedaan hasil pengukuran yang mencolok antara lokasi sekolah dasar (SD) yang berada di lingkungan lalu lintas padat dan tidak padat.

Pada satu titik lokasi di lingkungan lalu lintas padat terdapat hasil pengukuran kadar TSP yang melebihi standar baku mutu yaitu sebesar $237,04 \mu \mathrm{g} / \mathrm{m}^{3}$. Terdapat perbedaan hasil pengukuran yang mencolok antar lokasi SD yang terletak di lingkungan lalu lintas padat dan tidak padat. Nilai dan kategori indeks standar pencemar udara (ISPU)

Tabel 1. Nilai dan kategori ISPU di lokasi penelitian

\begin{tabular}{|c|c|c|c|c|c|c|}
\hline \multirow{3}{*}{ Parameter } & \multicolumn{6}{|c|}{ Nilai dan Kategori ISPU } \\
\hline & \multicolumn{3}{|c|}{ Lingkungan Padat } & \multicolumn{3}{|c|}{$\begin{array}{c}\text { Lingkungan Tidak Padat } \\
\end{array}$} \\
\hline & $\begin{array}{c}\text { Rerata } \\
\text { konsentrasi }\end{array}$ & Indeks & Kategori & $\begin{array}{c}\text { Rerata } \\
\text { konsentrasi }\end{array}$ & Indeks & Kategori \\
\hline $\mathrm{SO}_{2}$ & 19,6 & 12,8 & Baik & 10,4 & 6,5 & Baik \\
\hline $\mathrm{NO}_{2}$ & 20,9 & $*<50$ & Baik & 10,9 & $*<50$ & Baik \\
\hline $\mathrm{O}_{3}$ & 16,1 & 6,7 & Baik & 10,4 & 4,3 & Baik \\
\hline $\mathrm{PM}_{10}^{* *}$ & 124,1 & 87,1 & Sedang & 48,1 & 48,1 & Baik \\
\hline
\end{tabular}

Keterangan:

*Konsentrasi < 1.130 sebagai batas minimal perhitungan indeks

**Nilai $\mathrm{PM}_{10}$ diperoleh dari hasil perhitungan 0,55 dari nilai TSP 
Tabel 2. Ciri responden $(n=115)$

\begin{tabular}{lcc}
\hline \multicolumn{2}{c}{ Karakteristik } & \multicolumn{2}{c}{ Persentase } \\
\cline { 2 - 3 } & Padat & Tidak Padat \\
\hline Jenis Kelamin & 55 & 54 \\
Perempuan & $45)$ & 46 \\
Laki-laki & & \\
Paparan rokok di rumah & & 80 \\
Tidak ada & 71 & 20 \\
Ada & 29 & \\
Status gizi & & 87 \\
Normal & 63 & 13 \\
Tidak normal & 37 & \\
Kebiasaan olahraga & & 22 \\
Ya & 21 & 78 \\
Tidak & 79 & \\
Fungsi paru & & 80 \\
Normal & 57 & 20 \\
Tidak normal & 43 & \\
\hline
\end{tabular}

Tabel 2 menunjukkan ada hubungan antara kadar $\mathrm{SO}_{2}, \mathrm{NO}_{2}, \mathrm{O}_{3}$, dan TSP $(\mathrm{p}<0,05)$ di udara ambien dengan fungsi paru siswa, namun setelah dilakukan analisis bersama faktor lain, kadar TSP di udara ambien merupakan faktor yang sangat berpengaruh dalam menimbulkan gangguan fungsi paru.

Tabel 3. Analisis bivariat

\begin{tabular}{lccc}
\hline & \multicolumn{2}{c}{ Fungsi Paru } & p \\
\cline { 2 - 3 } & $\begin{array}{c}\text { Normal } \\
(\mathbf{n}=\mathbf{8 0})\end{array}$ & $\begin{array}{c}\text { Tidak } \\
(\mathbf{n}=35)\end{array}$ & \\
\hline $\mathrm{SO}_{2}$ & 11,01 & 17,4 & $0,024^{*}$ \\
& $(9,3-23,9)$ & $(9,3-23,9)$ & \\
$\mathrm{NO}_{2}$ & 11,7 & 19,8 & $0,029^{*}$ \\
& $(9,5-23,6)$ & $(9,5-23,6)$ & \\
$\mathrm{O}_{3}$ & 11,05 & 15,0 & $0,023^{*}$ \\
& $(9,1-17,6)$ & $(9,1-17,6)$ & \\
$\mathrm{TSP}$ & 97,02 & 211,0 & $0,023^{*}$ \\
& $(67,9-237,0)$ & $(67,9-237,0)$ & \\
\hline
\end{tabular}

\section{BAHASAN}

Penelitian sebelumnya menyatakan bahwa kadar TSP dan $\mathrm{O}_{3}$ pada udara ambien merupakan faktor yang erat berhubungan dengan penurunan fungsi paru dan kesehatan (11). Penelitian lain menyebutkan bahwa paparan polusi udara berupa partikel dan $\mathrm{NO}_{2}$ menurunkan fungsi paru pada siswa sekolah. Semakin muda usia siswa terpapar dan semakin lama ia terpapar, maka hubungan itu akan semakin kuat (10). Selain itu, keberadaan $\mathrm{O}_{3}$ di udara meskipun dalam kadar yang masih di bawah nilai ambang batas yang ditetapkan World Health Organization (WHO) dapat menurunkan fungsi paru pada anak (14). Kualitas udara yang diukur dengan parameter $\mathrm{SO}_{2}$, $\mathrm{NO}_{2}$ dan $\mathrm{PM}_{10}$ berhubungan dengan fungsi paru anak (12). Hal tersebut di atas sejalan dengan penelitian yang menyebutkan bahwa kualitas udara ambien berkaitan erat dengan gangguan pernapasan pada anak, kadar TSP di udara ambien menunjukkan hubungan yang lebih kuat dengan munculnya gangguan pernapasan dibanding kadar $\mathrm{SO}_{2}$ dan $\mathrm{NO}_{2}$ pada udara ambien (13).

Lebih lanjut dijelaskan bahwa terdapat hubungan antara polusi udara ambien dengan volume paru yang lebih rendah pada anak dan polusi udara merupakan bagian dari penyebab timbulnya reaksi yang mengakibatkan retardasi perkembangan fungsi paru anak $(14,15)$. Polusi udara dapat mengakibatkan berbagai gangguan kesehatan anak, di antaranya penurunan fungsi paru ketika polusi meningkat. Selain itu terdapat perbedaan fungsi paru pada wilayah dengan kadar polusi udara yang berbeda, anak yang tinggal di daerah dengan polusi lebih tinggi menunjukkan fungsi paru yang lebih rendah (16). Pencemaran udara oleh sulfur oksida $\left(\mathrm{SO}_{\mathrm{x}}\right)$ disebabkan oleh dua komponen gas oksida sulfur yang tidak berwarna, yaitu sulfur dioksida (SO2) dan sulfur trioksida $\left(\mathrm{SO}_{3}\right) . \mathrm{SO}_{2}$ mempunyai karakteristik bau yang tajam dan tidak mudah terbakar di udara, sedangkan $\mathrm{SO}_{3}$ adalah gas yang tidak reaktif (17).

$\mathrm{SO}_{2}$ didapat dari sumber alamiah dan sumber buatan. Sumber alamiah adalah gunung api, pembusukan bahan organik oleh mikroba dan reduksi sulfat secara biologis. Sumber-sumber $\mathrm{SO}_{2}$ buatan adalah pembakaran bahan bakar minyak, gas, dan batu bara yang mengandung sulfur tinggi. Sumber buatan ini diperkirakan memberi kontribusi sepertiga dari seluruh $\mathrm{SO}_{2}$ atmosfir per tahun (18).

Pengaruh utama polutan ini terhadap manusia adalah iritasi sistem pernapasan yang menyebabkan timbulnya kesulitan bernafas, terutama pada kelompok sensitif, seperti orang berpenyakit asma, anak-anak dan lansia. $\mathrm{SO}_{2}$ juga mampu bereaksi dengan senyawa kimia lain membentuk partikel sulfat yang jika terhirup dapat terakumulasi di paru-paru dan menyebabkan kesulitan bernapas, penyakit pernapasan, dan bahkan kematian $(1,17)$

Nitrogen Oksida yang terdapat di atmosfer adalah $\mathrm{NO}, \mathrm{NO}_{2}$ dan $\mathrm{N}_{2} \mathrm{O}$. Dari seluruh jumlah $\mathrm{NO}_{\mathrm{x}} \mathrm{di}$ atmosfer, jumlah terbanyak dalam bentuk NO yang diproduksi oleh aktivitas bakteri (18). Jumlah NO hasil bentukan bakteri tersebar merata sehingga kadar di udara menjadi kecil. yang menjadi masalah adalah polusi NO dari kegiatan manusia yang jumlahnya semakin meningkat (17). $\mathrm{NO}_{2}$ bersifat racun terutama terhadap paru. Kadar $\mathrm{NO}_{2}$ yang lebih tinggi dari 100 ppm dapat mematikan sebagian besar binatang percobaan dan $90 \%$ dari kematian tersebut disebabkan oleh gejala edema pulmonari. Pemajanan $\mathrm{NO}_{2}$ dengan kadar 5 ppm selama 10 menit terhadap manusia mengakibatkan kesulitan dalam bernapas $(1,17)$. 
Ozon adalah gas yang tidak stabil berwarna biru yang mudah mengoksidasi. Secara alamiah $\mathrm{O}_{3}$ terdapat di stratosfer dan sebagian di troposfir, yang merupakan konstituen dari smog. Selain itu $\mathrm{O}_{3}$ dihasilkan dari berbagai sumber seperti peralatan listrik bervoltase tinggi, peralatan sinar rontgen, dan spektograf (18).

Ozon dapat memasuki saluran pernapasan lebih dalam dari $\mathrm{SO}_{2}$, ozon mematikan sel-sel makrofag, menstimulir penebalan dinding arteri paru, dan pada paparan lama dapat mengakibatkan terjadinya kerusakan paru, yang disebut empisema,yang pada akhirnya melemahkan jantung. Hal ini terjadi karena pada empisema, dinding alveoli tidak elastis lagi, sehingga pada saat proses pernapasan tidak dapat mengembang dan tidak dapat berfungsi dalam pertukaran gas. Hal ini menyebabkantimbul robekan pada dinding alveoli $(1,17)$.

Partikel/partikulat adalah zat padat/cair yang halus dan tersuspensi ke udara yang terdiri atas zat organik dan anorganik, misalnya embun, debu, asap, fumes dan fog. Sifat fisik partikulat adalah ukurannya yang berkisar antara 0,0002-500 mikron, yang lama keberadaannya di udara tergantung kecepatan pe- ngendapan, yang ditentukan ukuran, densitas partikulat, dan aliran udara. Sumber partikulat adalah sumber alami dari atmosfer dan sumber lain yang menghasilkan debu seperti pabrik semen, konstruksi, dan kendaraan bermotor $(17,18)$.

Partikulat yang masuk dalam pernapasan dengan ukuran lebih dari 5 mikron akan terhenti dan terkumpul di dalam hidung dan tenggorokan, partikel dengan ukuran 0,5-5 mikron akan terkumpul dalam bronchioli paru dan partikel dengan ukuran <0,5 mikron amencapai alveoli. Hal ini membahayakan apabila partikel masuk dalam alveoli dan terarsobsi dalam darah mungkin mengandung racun (19).

Dari ke enam pemodelan di atas, model ke-6 memberikan penjelasan yang lebih baik tentang faktor-faktor yang berhubungan dengan fungsi paru siswa sekolah. Ketika keberadaan faktor itu secara bersama-sama terjadi, maka paparan rokok, kadar TSP di udara ambien dan kebiasaan olahraga adalah faktor-faktor yang signifikan dan bermakna berhubungan dengan fungsi paru siswa.

\section{SIMPULAN}

Penelitian menemukan perbedaan nilai median yang mencolok pada seluruh parameter kualitas udara ambien di SD yang berada di lingkungan lalu lintas padat dan tidak padat. Persentase fungsi paru siswa SD yang masuk dalam kategori tidak normal lebih banyak berada di lingkungan lalu lintas padat. Siswa yang sekolah di lingkungan padat mempunyai kemungkinan 2,7 kali mengalami gangguan fungsi paru. Faktor utama yang memengaruhi fungsi paru siswa adalah paparan rokok, kebiasaan olahraga dan kadar TSP. Kepala sekolah perlu mengaktifkan unit kesehatan sekolah (UKS) dan dokter kecil untuk menjauhkan siswa dari paparan asap.

\begin{abstract}
Abstrak
Tujuan: Tujuan penelitian ini adalah melihat hubungan kualitas udara ambien dengan fungsi paru siswa sekolah dasar. Metode:Jenis penelitian menggunakan rancangan potong lintang. Subyek penelitian berjumlah 115 siswa dari enam sekolah dasar. Variabel kualitas udara ambien $\left(\mathrm{SO}_{2}, \mathrm{NO}_{2}\right.$, $\mathrm{O}_{3}$, dan TSP) dihubungkan dengan fungsi paru anak. Hasil: Kualitas udara ambien pada SD yang berada di lingkungan lalu lintas padat dan tidak padat masih berada di bawah nilai ambang batas yang dipersyaratkan; Terdapat hubungan antara kadar $\mathrm{SO}_{2}, \mathrm{NO}_{2}, \mathrm{O}_{3}$, dan TSP $(\mathrm{p}<0,05)$ di udara ambien dengan fungsi paru siswa dan kadar TSP di udara ambien menjadi faktor utama yang berhubungan dengan fungsi paru setelah dilakukan analisis multivariat dengan faktor lokasi sekolah, jenis kelamin, status gizi, paparan rokok, dan kebiasaan olahraga. Simpulan: Faktor utama yang memengaruhi fungsi paru siswa adalah paparan rokok, kebiasaan olahraga dan kadar TSP. Kepala sekolah perlu mengaktifkan unit kesehatan sekolah (UKS) dan dokter kecil untuk menjauhkan siswa dari paparan asap.
\end{abstract}

Kata kunci: kualitas udara ambien; fungsi paru; siswa sekolah dasar 


\section{PUSTAKA}

1. Leithe W. The Analysis of Air Pollution. Michigan: Ann Arbor Science Publisher: 1971.

2. Centers for Disease Control. Populations at Risk from Air Pollution - United States, 1991, Morbidity and Mortality Weekly Report,.1993. vol 42,16.

3. Clark C., Head J., Stansfeld AS. Longitudinal effect of aircraft noise exposure on children's health and cognition: A six-year follow-up of the UK RANCH cohort. Journal of Environmental Psychology. 2013.Vol 35 pp 1-9.

4. Canadian Institute for Health Information Children Vulnerable in Areas of Early Development: A Determinant of Child Health, Ottawa. ON; CIHI: 2014.

5. Gauderman WJ., Vora H., McConel R., Berhane K., Gilland F., Thomas D., Lurmann F., Avol E., Kunzli N., Jerret M., Peters J. Effect of Exposure to Traffic on Lung Development from 10 to 18 Years of Age: a Cohort Study. The Lancet. 2007 369, 9561. Pg 571.

6. West JB.. Patofisiologi Paru Esensial Edisi 6. Jakarta : Penerbit Buku Kedokteran EGC: 2010.

7. Hwang FB., Chen HY., Lin TY., Wu TX., Lee LY. Relationship between exposure to fine particulates and ozone and reduced lung function in children. Environmental Research, 2015. 137 pp 382-390.

8. Asgari M., Dubois A., Gent J., Beckett W. Association of Ambient Air Quality with Children's Lung Function in Urban and Rural Iran. Environmental Health. 1998. 53.3 pg.222.

9. Brunekreef B., Janssen NAH., Hartog J., Harssema H., Knape M., Vliet P. . Air Pollution from Truck Traffic and Lung Function in Children Living near Motorways. Epidemiology. 1997. Vol 8.3pp 298-303.
10. Frye C., Hoelscher B., Cyrys J., Wjst M., Wichmann HE., Heinrich J. Association of Lung Function with Declining Ambient Air Pollution. Environmental Health Perspective. 2003. Vol 111, 16. 383-387.

11. Oftedal B., Brunekreef B., Nystad., Madsen., Walker SE., Nafstad P. Residential Outdoor Air Pollution and Lung Function in Schoolchildren Epidemiology. 2008. 19 (1) pp 129-137.

12. Mathew J., Goyal R., Taneja KK., Arora N. Air Pollution and Respiratory Health of School Children in Industrial, Commercial and Residential Areas of Delhi. Air Qua Atmos Health. 2014. 014-0299 pp 1982-1989.

13. Rabee AM. Estimating the Health Risks Associated with Air Pollution in Baghad City, Iraq. Environmental Monitoring Assesment . 2015. 187.

14. Pan G., Zhang S., Feng Y., Takahasbi K., Kagawa J, Yu L., Wang P., Liu M., Liu Q., Hou S., Pan B., Li J. Air Pollution and Children's Respiratory Symptoms in Six Cities of Northern China. Respiratory Medicine. 2010. 104 pp 1903-1911.

15. Amadeo B., Robert C., Rondeau V., Mounouchy AM., Cordeau L., Birembaux X., Citadelle E., Got J., Gouranton M., Marcin G., Laurac D., Ragerison C. Impact of Close-Proximity Air Pollution on Lung Function in Schoolchildren in French West Indies. BMC Public Health.2015. 15 (45) pp 1-12.

16. Jedrychowski W., Flak E., Mroz E. The Adverse Effect of Low Levels of Ambient Air Pollutants on Lung Function Growth in Preadolescent Children. Environmental Health Perspectives. 1999. 107 pp 669-674.

17. Bates DV. The Effects of Air Pollution on Children. Environmental Health Perspectives. 1995. Vol 103 pp 49-53.

18. Fardiaz S. Polusi Air dan Udara. Yogyakarta: Penerbit Kanisius: 1992.

19. Soemirat J. Kesehatan Lingkungan. Yogyakarta : Gadjah Mada University Press: 2014. 
Berita Kedokteran Masyarakat, Volume 32 No. 3 Tahun 2016 